\title{
O ensino dos CPCs nos cursos de ciências contábeis em instituições de ensino superior do Brasil
}

Teaching of CPCs in accounting courses in higher education institutions in Brazil

Enseñanza del CPCs en cursos de contabilidad en instituciones de educación superior de Brasil

\section{Diego Saldo Alves}

Mestre em Ciências Contábeis pela Universidade do Vale do Rio dos Sinos (UNISINOS)

Professor do Curso de Graduação em Ciências Contábeis na Universidade Feevale

Endereço: ERS-239, 2755, Vila Nova

CEP: 93525-075 - Novo Hamburgo/RS - Brasil

E-mail: diego.acta@gmail.com

Telefone: (51) 981360510

\section{Clóvis Antônio Kronbauer}

Doutor em Contabilidade e Auditoria pela Universidade de Sevilha - Espanha

Professor do PPG de Ciências Contábeis na Universidade do Vale do Rio dos Sinos (UNISINOS)

Endereço: Av. Unisinos, 950, Cristo Rei

CEP: 93022-000 - São Leopoldo/RS - Brasil

E-mail: clovisk@unisinos.br

Telefone: (51) 3591-1122

\section{Ernani Ott}

Doutor em Ciências Econômicas e Empresariais pela Universidade de Deusto - Espanha Professor do PPG de Ciências Contábeis na Universidade do Vale do Rio dos Sinos (UNISINOS)

Endereço: Av. Unisinos, 950, Cristo Rei

CEP: 93022-000 - São Leopoldo/RS - Brasil

E-mail: ernani@unisinos.br

Telefone: (51) 3591-1122

\section{João Luis Peruchena Thomaz}

Mestre em Ciências Contábeis pela Universidade do Vale do Rio dos Sinos (UNISINOS)

Professor do Curso de Graduação em Ciências Contábeis na Universidade Federal do Pampa

Endereço: Av. General Osório, 900, Centro

CEP: 96400-100 - Bagé/RS - Brasil

E-mail: jlthomaz@tradecontabil.com.br

Telefone: (53) 3240-5400

Artigo recebido em 24/03/2016. Revisado por pares em 29/08/2016. Reformulado em 15/03/2017. Recomendado para publicação em 26/05/2017 por Carlos Eduardo Facin Lavarda (Editor-Chefe). Publicado em 31/08/2017. 


\title{
Resumo
}

Este estudo tem como objetivo analisar se os conteúdos de contabilidade constantes nos currículos dos cursos de ciências contábeis em instituições de ensino superior (IES) no Brasil estão alinhados com os Pronunciamentos Técnicos (CPC), que têm origem nas normas internacionais de contabilidade. A amostra é formada por 105 instituições de ensino superior do Brasil que oferecem o curso de ciências contábeis na modalidade presencial e que disponibilizaram suas ementas e/ou conteúdos programáticos. As análises dos dados basearamse em tabelas, gráficos e quadros, embasados em técnicas de estatística descritiva e também avaliação de diferenças de médias de aderência por região, organização acadêmica e categoria acadêmica. Conclui-se, neste estudo, que as IES no Brasil pertencentes à amostra possuem baixa aderência em relação aos CPCs, o ensino da contabilidade harmonizado aos padrões internacionais necessita de melhorias que contemplem um número maior de CPCs nos conteúdos programáticos das IES.

Palavras-chave: Ensino; Contabilidade; Normas Internacionais; CPC

\begin{abstract}
This study aims to analyze whether the accounting content in the curricula of Accounting courses in higher education institutions in Brazil are aligned with the Technical Pronouncement $C P C$ which origins are the international accounting standards. The research is classified as descriptive, documentary, qualitative and quantitative. The sample consists of 105 higher education institutions in Brazil that offer the Accounting course in classroom mode and publish their syllabus and/or program content on their web sites or through e-mail by the coordinators of Accounting courses. The analysis of the data relied on tables, graphs, charts, based on descriptive statistics and also evaluation of differences in means of adherence by region, academic organization and academic category. It is concluded in this study that IESs in Brazil belonging to the sample have low adherence in relation to CPCs.
\end{abstract}

Keywords: Education; Accounting; International Standards; $C P C$

\section{Resumen}

Este estudio tiene como objetivo analizar si el contenido de la contabilidad constante en los planes de estudio de los cursos en ciencias contables en las instituciones de educación superior (IES) en Brasil, están alineados con la Resoluciones Técnicas (CPC), que se originan en las normas internacionales de contabilidad. La muestra se compone de 105 instituciones de educación superior en Brasil que ofrecen el curso de contabilidad en la modalidad presencial y ofreciendo sus menús y / o programa de estudios. Análisis de datos se basan en tablas, gráficos, basado en la estadística descriptiva y también mediante una evaluación de las diferencias de medias de adhesión por regiones, la organización académica y la categoría académica. La conclusión, en este estudio, que las IES en Brasil perteneciente a la muestra tienen una baja adhesión con respecto a CPC, de la enseñanza de la contabilidad armonizada con los estándares internacionales requieren mejoras que incluyen un mayor número de CPC en el contenido de la IES.

Palabras clave: Educación; Contabilidad; Normas Internacionales; CPC

\section{Introdução}

O progresso econômico exige profissionais qualificados para atuarem nas empresas; em consequência desse progresso, os profissionais necessitam de boas condições de ensino para a sua formação (PELEIAS et al., 2007). 
As relações entre as empresas e seus stakeholders internacionalizaram-se e, em decorrência, houve a necessidade de harmonização das normas contábeis. Essa harmonização é um processo difícil, devido a diferenças culturais, legais, econômicas, históricas e profissionais. Nesse contexto de internacionalização, o mercado necessita de profissionais mais qualificados para atuar dentro e fora do país. Por conseguinte, os contadores estão buscando cursos que complementem a sua formação, já que os cursos de graduação em ciências contábeis, na grande maioria, limitam-se à contabilidade nacional (CZESNAT; CUNHA; DOMINGUES, 2009).

No Brasil, foi promulgada a Lei $\mathrm{n}^{0} 11.638 / 2007$, que modificou a lei das sociedades anônimas. A nova lei impôs alterações significativas, como a adoção das normas brasileiras de contabilidade em conformidade com as normas internacionais, os International Financial Reporting Standards (IFRS) (CUNHA et al., 2013).

A harmonização das normas internacionais de contabilidade no Brasil e nos países que adotaram os IFRS alterou significativamente a rotina da contabilidade das indústrias, comércio, serviços e demais setores. A partir da adoção, estas empresas passaram a seguir as normas do International Accounting Standards Board (IASB) - no Brasil, especificamente, as do CPC. No país, desde então, os profissionais tiveram que se atualizar com os Pronunciamentos Técnicos emitidos pelo $\mathrm{CPC}$, visto que um número significativo de profissionais já adotava anteriormente as Normas Internacionais de Contabilidade.

A adoção das IFRS não afetou somente indústria, comércio e serviços, mas também as Instituições de Ensino Superior, principalmente as que oferecem o curso de Ciências Contábeis. Após a adoção das Normas Internacionais de Contabilidade no Brasil, presume-se que os cursos de Ciências Contábeis em IES devem contemplar nos conteúdos programáticos as normas internacionais de contabilidade, atendendo assim as necessidades do mercado e as exigências ou sugestões de órgãos que trabalham para que o ensino da contabilidade esteja harmonizado com as normas internacionais de contabilidade como ONU, CFC e as diretrizes curriculares do Ministério da Educação (MEC), entre outros.

Esta mudança na contabilidade no Brasil relaciona-se diretamente com as IES no que tange o ambiente institucional, tanto interno como externo, no qual as entidades estão inseridas. Segundo North (1995), as organizações assumem a função de estabelecer por meio de incentivos, regras e restrições aos negócios, capacitadas a influenciar sobre a regulação das relações entre grupos sócias ou indivíduos.

A Organização das Nações Unidas (ONU), por meio da United Nations Conference on Trade and Development (UNCTAD), que é o órgão responsável pela pesquisa e debate de temas contábeis, com o seu grupo de trabalho, o Intergovernmental Working Group of Experts on International Standards of Accounting and Reporting (ISAR), elaborou um currículo mundial de estudos de contabilidade. A proposta da ONU/UNCTAD/ISAR descreve questões técnicas que os estudantes devem aprender para exercer a profissão contábil (MAGALHÃES; ANDRADE, 2006).

As Diretrizes Curriculares Nacionais para o curso de Graduação em Ciências Contábeis foram instituídas pela Resolução CNE/CES n 10/2004. Niyama et al. (2008) afirmam que o conteúdo mínimo da grade curricular para os cursos de ciências contábeis é regido por essa resolução, assim como devem fazer parte do projeto pedagógico e da organização curricular do curso de graduação em ciências contábeis os conteúdos que abordam conhecimento dos cenários econômicos e financeiros, tanto nacionais como internacionais, e que proporcionam a harmonização das normas e padrões internacionais de contabilidade.

O Conselho Federal de Contabilidade apresentou uma proposta nacional de conteúdos para o curso de ciências contábeis. A motivação para essa proposta vem das diferenças de 
matrizes curriculares existentes entre os cursos, dificultando um estudo mais equilibrado em termos de conteúdo. (RODRIGUES et al., 2009).

Em função das necessidades de convergência internacional das normas contábeis, centralização na emissão dessas normas, representação e processo democrático na produção das informações, criou-se o Comitê de Pronunciamentos Contábeis (CPC, 2013).

Nesse contexto do ensino de contabilidade harmonizada pelo Conselho Federal de Contabilidade (CFC) aos padrões internacionais e à proposta de currículo apresentada pela ONU/UNCTAD/ISAR, apresenta-se o seguinte problema de pesquisa: os conteúdos de contabilidade constantes nos currículos dos cursos de ciências contábeis em IES no Brasil estão alinhados com os pronunciamentos técnicos do CPC, que têm origem nas normas internacionais de contabilidade?

Considerando o problema de pesquisa apresentado, tem-se como objetivo geral analisar se os conteúdos de contabilidade constantes nos currículos dos cursos de ciências contábeis em IES no Brasil estão alinhados com os pronunciamentos técnicos do CPC, que têm origem nas normas internacionais de contabilidade.

O estudo justifica-se pelo fato do Brasil ter adotado as Normas Internacionais de Contabilidade (IFRS) a partir de 2008, com a promulgação da Lei 11.638/2007. Desde então, a prática contábil no país está baseada na interpretação dos pronunciamentos técnicos do Comitê de Pronunciamentos Técnicos (CPC). A adoção das IFRS consequentemente provoca uma mudança institucional nas IES que oferecem o curso de Ciências Contábeis, dessa forma, é importante analisar se as IES estão modificando as suas ementas e conteúdos programáticos para se adequar as normas sugeridas pelos órgãos responsáveis. O estudo é relevante para a comunidade acadêmica, empresários, ministério da educação e demais órgãos envolvidos, como forma de avaliar o ensino da contabilidade no Brasil.

Este estudo tem importância significativa para as IES brasileiras que oferecem o curso de ciências contábeis. Por meio desse estudo, é possível analisar se os CPCs estão contemplados nas ementas e/ou conteúdos programáticos dos cursos de ciências contábeis em IES do Brasil. O estudo é relevante por ser uma pesquisa inédita, e ajudará as IES no Brasil que oferecem o curso de ciências contábeis a adequar o ensino da contabilidade aos padrões internacionais. $\mathrm{O}$ estudo também servirá para que os coordenadores dos cursos de ciências contábeis possam refletir e verificar se estes estão alinhados aos padrões internacionais de contabilidade.

\section{Revisão da Literatura}

\subsection{Proposta de Currículo pela ONU/ISAR/UNCTAD e o CFC}

A palavra currículo tem origem no latim curriculum, que significa caminho, trajetória, percurso, pista de corrida. Esta palavra também indica travessia, com pontos de partida e de chegada (MORAES, 2010).

Segundo Malta (2013), o currículo era concebido como uma questão técnica pelas perspectivas tradicionais, que se resumiam em discutir as mais eficientes e melhores formas de organizar o currículo e em aceitar os conhecimentos e os saberes dominantes, pretendendo, dessa forma, ser teorias científicas, neutras ou desinteressadas.

Se fosse solicitada uma definição de currículo, poderíamos encontrar uma grande variedade de definições. Estudiosos como Silva (2000, 2001, 2007), Moreira (2001), Sacristán (2000), Goodlad (1979), Yamamoto e Romeu (1983) e demais autores já identificaram em torno de trinta conceitos. Cada conceito está comprometido, de forma explícita ou não, com uma teoria de aprendizagem, corrente pedagógica ou com uma época histórica. (MALTA, 2013). 
Segundo Malta (2013), frequentemente o currículo é usado para designar o programa de um curso inteiro, uma disciplina ou, em um sentido mais amplo, descrito como contemplando diversas atividades educacionais, das quais o conteúdo é desenvolvido abrangendo também materiais e metodologias utilizadas. Quando se pergunta o que é currículo, não se trata de escolher a definição mais aceita pela comunidade científica, a definição mais moderna ou a mais divulgada mas, sim, entender currículo como o agir e o pensar em relação às seguintes questões: a quem ensinar? Como ensinar? O que ensinar? Para que ensinar?

As questões levantadas por Malta (2013) podemos direcionar ao ensino das normas internacionais de contabilidade. Por exemplo: "a quem ensinar?" - podemos ensinar aos estudantes de ciências contábeis, administração, economia e demais usuários das informações contábeis. Esse conhecimento não pode ser limitado. Já a questão "como ensinar?" deve ser adaptada a cada curso de graduação ou pós-graduação e aos demais usuários das informações, pois ensinar para estudantes de ciências contábeis e economia demandará uma abordagem diferente. A questão "o que ensinar?" é bem adequada aos objetivos deste trabalho, que analisa quais CPCs estão sendo ensinados nas IES do Brasil. A última questão levantada por Malta (2013), "para que ensinar?", também está bem adequada ao objeto de estudo deste trabalho. Por que os CPCs devem ser ensinados nos cursos de ciências contábeis?

Para Cunha (2011), as discussões sobre currículo constituem uma das problemáticas mais complexas na área da educação, pois discutir currículo é o mesmo que discutir a própria educação formal, ainda que se queira abordar a política curricular, as representações sobre diversos elementos, a prática pedagógica, as questões das diversidades, a organização e demais questões.

A Organização das Nações Unidas (ONU), por meio da Nations Conference on Trade and Development (UNCTAD) e do International Standards of Accounting and Reporting (ISAR), criou uma proposta de currículo para os cursos de ciências contábeis. Essa proposta pode ser utilizada como guia para as instituições de ensino superior na elaboração de programas curriculares. Denominada como Currículo Mundial (CM), apresenta os principais conhecimentos que o contador deve adquirir para poder atuar profissionalmente em qualquer país (CAMPOS; LEMES, 2011).

Riccio e Sakata (2004) citam que as mudanças ocasionadas pela globalização e pela harmonização das normas contábeis estimulam as instituições de ensino contábil de diversos países a adequar-se a essa nova realidade. Para os autores, deveria haver uma convergência das grades curriculares de contabilidade entre diversos países, no intuito de formar profissionais com características semelhantes.

No ano de 1999, o ISAR publicou dois documentos relacionados à elaboração de um currículo mundial de estudos em contabilidade. $O$ primeiro documento foi $o$ TD/B/COM.2/ISAR/5, denominado Guideline on National Requirements for the Qualification of Professional Accountants, que trata de um programa mundial de estudos de contabilidade e normas contábeis. O segundo é o TD/B/COM.2/ISAR/6(TD6), denominado de Global Curriculum for the Professional Education of Professional Accountants, que trata de um programa de estudos mais detalhado (FROSI, 2013).

Aggestam (1999) menciona que o conceito de qualificação global proposto pelo ISAR está relacionado com a harmonização e qualificação dos profissionais contábeis, que são educados e certificados com base nos modelos de cada país.

Pires (2008) cita que o guia para qualificação dos profissionais contábeis elaborado pelo ISAR sugere algumas práticas a serem seguidas, como: educação geral, habilidade inerentes aos contadores, educação profissional, exame de suficiência, experiência prática, educação continuada e certificação. Em relação aos conhecimentos técnicos exigidos pelo ISAR, no item 
educação profissional são divididos em conhecimentos administrativos organizacionais, conhecimento de tecnologia da informação e conhecimentos contábeis e assuntos afins.

Os conhecimentos técnicos foram alterados na $20^{\circ}$ sessão do ISAR em 2003, atualizando o documento elaborado em 1999. Esse documento deu origem ao Revised Model Accounting Curriculum (MC), que descreve os conteúdos relacionados a cada um dos blocos de conhecimento (PIRES, 2008).

O Conselho Federal de Contabilidade (CFC) criou, por meio da Portaria CFC n ${ }^{\circ} 10 / 06$, de 3 de fevereiro de 2006, com o apoio da Fundação Brasileira de Contabilidade (FBC), uma comissão para elaborar a Proposta Nacional de Conteúdo para o Curso de Graduação em Ciências Contábeis. O CFC teve por base a Resolução CNE/CES n ${ }^{0}$ 10/04 de 10 de dezembro de 2004 (Diretrizes Curriculares Nacionais do Curso de Ciências Contábeis).

Em 2009 um grupo de professores elaborou a $2^{\text {a }}$ edição, revisada e atualizada, da proposta do CFC. A $2^{\mathrm{a}}$ edição foi necessária devido às mudanças ocorridas no cenário da contabilidade com a lei 11.638/2007. O objetivo da segunda edição é apresentar às IES, coordenadores de curso e professores um trabalho de pesquisa com sugestões de disciplina que devem compor a grade curricular dos cursos de ciências contábeis no Brasil, tanto na modalidade presencial quanto na semipresencial e a distância (proposta CFC, 2009, p. 5).

Na proposta do CFC $(2009$, p. 21) em relação aos conteúdos, são apresentados, para cada disciplina, ementário, conteúdo programático, sugestões bibliográficas, carga horária e objetivos gerais. São contemplados também, modelos de regulamento e diretrizes de trabalho de conclusão de curso (TCC), atividades complementares e estágio para o curso de Bacharelado em Ciências Contábeis.

A proposta de Conteúdo de Formação Básica é baseada no disposto da Resolução CNE/CES no 10/2004, e o seu conteúdo é composto pelas seguintes disciplinas: matemática, métodos quantitativos aplicados, matemática financeira, comunicação empresarial, economia, administração, instituições de direito público e privado, direito comercial, legislação societária, direito trabalhista, legislação social, direito, legislação tributária, ética, legislação profissional, filosofia da ciência, metodologia do trabalho científico, psicologia organizacional e tecnologia da informação.

A proposta do CFC atualizada em 2009 já está alinhada com os CPCs. Em relação à Estrutura das Demonstrações Contábeis, a ementa já menciona alguns CPCs, como Demonstração dos Fluxos de Caixa e Demonstração do Valor Adicionado. Quanto à Contabilidade Societária, também já contempla alguns CPCs, mesmo que de forma indireta, como, por exemplo, Combinação de Negócios, Ajuste a Valor Presente, Valor Justo, Redução ao Valor Recuperável dos Ativos, Ativos e Passivos Contingentes, entre outros.

O ensino da contabilidade no Brasil também está sustentado pelos pronunciamentos técnicos emitidos pelo CPC, assunto abordado a seguir.

\subsection{Convergência das Normas Internacionais de Contabilidade}

No Brasil, foi promulgada a Lei $\mathrm{n}^{\mathrm{o}} 11.638 / 2007$, que modificou a lei das sociedades anônimas. A Lei 11.638/2007 impôs alterações significativas, como a adoção das normas brasileiras de contabilidade em conformidade com as normas internacionais, os International Financial Reporting Standards (IFRS) (CUNHA et al., 2013).

Em função das necessidades de convergência internacional das normas contábeis, centralização na emissão dessas normas, representação e processo democrático na produção das informações, criou-se o Comitê de Pronunciamentos Contábeis (CPC).

O Comitê de Pronunciamentos Contábeis (CPC) foi criado pela Resolução CFC n ${ }^{\circ}$ $1.055 / 05$ e tem como objetivo o estudo, o preparo e a emissão de pronunciamentos técnicos 
sobre procedimentos de contabilidade e a divulgação de informações dessa natureza para permitir a emissão de normas pela entidade reguladora brasileira, visando à centralização e uniformização do seu processo de produção, levando sempre em conta a convergência da contabilidade brasileira aos padrões internacionais. (CPC, 2013).

Com a finalidade de dar mais consistência à pesquisa e à própria revisão da literatura, foram pesquisados artigos nacionais e internacionais sobre o ensino da contabilidade, estudos como:

Niyama et al. (2008) analisaram a aderência das instituições de ensino superior localizadas nas capitais brasileiras em relação ao conhecimento de contabilidade internacional. Os autores concluíram que nem todas as instituições de ensino superior das capitais brasileiras capacitam os estudantes quanto à contabilidade internacional. Também destacam que existem instituições que não ministram a disciplina de contabilidade internacional ou similar. Pode-se inferir que os profissionais que estão começando no mercado de trabalho na área contábil, possuem limitações em relação ao conhecimento as normas internacionais de contabilidade, especificamente nos Pronunciamentos Técnicos emitidos pelo CPC. Essa limitação na formação dos profissionais da área contábil pode elevar os custos das empresas devido a adoção de critérios contábeis indevidos e a necessidade de contratação de consultoria externa para suprir questões de conhecimento técnico.

Vysotskaya e Prokifieva (2013) analisaram as dificuldades de ensinar o IFRS na Rússia. Segundo as autoras, o atual estado de ensino do IFRS na Rússia reflete o problema que tem sido encontrar professores com experiência em indústria. O ensino da contabilidade na Rússia possui um enfoque em contabilidade fiscal devido ao sistema de tributação adotado naquele país. No Brasil também há dificuldade de encontrar professores com experiência prática em IFRS, já que a contabilidade tributária demanda muito tempo dos profissionais da área.

Hilton e Johnstone (2013) analisaram o impacto da adoção das IFRS no Canadá no ensino da contabilidade naquele país. Os autores analisaram como os professores se adaptaram a essa transição que ocorreu em 2010. A transição para o IFRS forneceu oportunidades para os professores canadenses revisarem o currículo de contabilidade e forma pedagógica de ensino. Os educadores canadenses tiveram que repensar o currículo, em muitos casos, a transição para o IFRS não resultou em mudanças substanciais, devido a similaridade do projeto pedagógico e o IFRS. Com a adoção do IFRS havia a preocupação em não sobrecarregar os conteúdos em relação ao ensino da contabilidade internacional, apenas ensinar o que é mais importante.

Campos e Lemes (2011) realizaram um estudo comparativo do Currículo Mundial (CM) proposto pela ONU/UNCTAD/ISAR, com o currículo adotado por Universidade Federais da região Sudeste do Brasil. A similaridade média encontrada pelos autores foi de $55,57 \%$ em relação ao CM. No que tange a contabilidade internacional contempladas no Bloco 3 e Bloco 4 proposto no $\mathrm{CM}$ a média foi de $64 \%$ e $39 \%$ respectivamente. Em relação ao Bloco 4 que contempla a apresentação das Demonstrações Contábeis e Contabilidade Gerencial, é um índice baixo, dessa forma, há necessidade de melhorias no que se refere ao ensino de contabilidade harmonizada as normas internacionais de contabilidade.

Frosi (2013) analisou o alinhamento dos currículos dos cursos de Ciências Contábeis em IES da região sul do Brasil, à proposta de currículo do Conselho Federal de Contabilidade. Os achados da autora evidenciam um alinhamento próximo de $80 \%$ ao currículo do CFC. Comparando o alinhamento dos currículos por estado comprovou-se estatisticamente que há uma igualdade nas médias de alinhamento nos cursos das IES do Rio Grande do Sul e Paraná e diferenças nas médias entre Rio Grande do Sul, e Santa Catarina e Santa Catarina e Paraná. Em relação as IES públicas e privadas, o percentual médio de alinhamento dos currículos é superior ao observados nas IES públicas, demonstrou-se estatisticamente a impossibilidade de igualdade entre os percentuais. 
Observa-se em estudos anteriores que o ensino da contabilidade harmonizado as normas internacionais é um assunto discutido no Brasil e também em outros países, pois há preocupação com a formação profissional alinhada com as normas internacionais. A adoção das normas internacionais não alterou somente as técnicas de contabilização e interpretação das informações contábeis, mas também alterou as rotinas e procedimentos das organizações, principalmente as IES do Brasil. As alterações nestas instituições podem ser explicada pela Teoria Institucional, assunto abordado no tópico seguinte.

\subsection{Teoria Institucional}

Nas discussões sobre as novas tendências teóricas e de investigação sociológicas, é consenso apontar a perspectiva institucional como um dos construtos teóricos mais promissores junto com as perspectivas ecológica e de redes, na intenção de explicar o funcionamento e evolução da sociedade organizacional (CARVALHO; VIERIA; SILVA; 2005). Este estudo, encontra-se na esteira desta perspectiva teórica, a partir do momento que o Brasil adotou as normas internacionais de contabilidade em 2008, com a vigência da Lei $n^{0} 11.638 / 2007$, o que ocasionou a alteração da sua matriz institucional.

De acordo com a teoria institucional, as instituições são limitações idealizadas pelo homem, com a função de organizar a interação humana, seja no campo social, político ou econômico. A teoria institucional também serve como explicação para evolução da sociedade ao longo do tempo, dessa forma, a relação entre indivíduos e a organização da sociedade é compreendida somente com a presença de regras, sendo que há diversos significados para regras (NORTH, 1995). Nesse contexto, a adoção das normas internacionais de contabilidade, na medida em que incorpora novos critérios e procedimentos de mensuração, reconhecimento e evidenciação, passa a adotar um novo comportamento que poderia influenciar nas relações econômicas, no caso as Instituições de Ensino Superiro (IES), objeto deste estudo.

$\mathrm{Na}$ vertente econômica, a origem da teoria institucional começa em 1898 com a publicação do artigo "Por que a economia não é uma ciência evolutiva?". A ideia central desse artigo foi a crítica aos pressupostos metodológicos da economia clássica, na concepção do homem como indivíduo racionalista e da capacidade máxima de racionalidade de suas escolhas (SECKLER, 1977)

John R. Commons e Wesley C. Mitchell junto com Thorstein Veblen, no início do século XX formavam a base intellectual do institucionalismo econômico. Embora houvesse diferenças entre eles, os três compartilhavam a precedência dos dados empíricos, também o foco em problemas práticos e a crítica à economia como conjunto de leis universais (SCOTT, 1995). Para Veblen (1965) o comportamento da economia está relacionado diretamente com os costumes e convenções adotados, e a ação de cada indivíduo é fator decisivo na evolução da economia, já que o conhecimento e hábitos do homem emolduram esse processo evolutivo.

Segundo Hodgson (2006) as principais ideias da "velha economia institucional (VEI)" são as instituições, os hábitos e as regras. A VEI busca entender como os hábitos e regras se transmitem e replicam, por esse motivo, esta perspectiva teórica pressupõe uma análise criteriosa da evolução de hábitos e regras específicas ao longo do tempo. Enquanto a velha economia institucional assume que as escolhas racionais são explicadas pelos hábitos, a nova economia institucional assume que os hábitos são consequência das escolhas racionais. Para o autor, os hábitos estão relacionados ao conhecimento e às crenças, sendo que o essencial das crenças ocorre devido ao estabelecimento de hábitos.

Para o institucionalismo, a ideia de comportamento humano baseado nos hábitos, só por si, não permite evoluir para uma análise ou teorização operacional, são necessários mais elementos para essa evolução. É importante entender como os hábitos coletivos são reforçados 
e integrados pelas instituições. Dessa forma, o institucionalismo parte do abstrato para o concreto, e recorre a outras áreas do conhecimento sobre comportamento dos indivíduos, como a antropologia, psicologia e a sociologia. (HODGSON; 2006).

A vertente sociológica da abordagem institucional assim como outras vertentes também recebe os qualificativos de velho e novo, mesmo que ambos estejam apoiados na tradição sociológica de Durkheim e Weber (CARVALHO; VIEIRA; SILVA; 2003).

Para Dimaggio e Powell, (1983) a Nova Sociologia Institucional (NSI) assume que as instituições que operam em condições ambientais similares, estão sujeitas a pressões externas, e que assumem estas pressões como comportamento adequado, incluindo a escolha e a forma que escolhem as estruturas e procedimentos internos. Dessa forma, as organizações tenderão refletir as regras, mitos, procedimentos e normas que prevalecem na sociedade. Segundo Scott (1991) a NSI baseia-se na ideia que as organizações são influenciadas pelos múltiplos aspectos do ambiente externo em que atuam. Para os teóricos da NSI as estruturas organizacionais são o resultado de pressões ambientais, as quais determinam a mudança das organizações.

O processo de mudança institucional envolve modificações nas regras formais e informais. As mudanças das restrições informais, ocorrem de forma mais gradativa do que as formais, no caso das limitações informais, as mudanças institucionais podem ter uma certa resistência devido a aspectos comportamentais, como por exemplo, o desenvolvimento de padrões alternativos pelo homem (NORTH, 1995). Segundo Bell (2011) o processo de mudança institucional é contínuo, lento e gradativo, passível de descontinuidade e ruptura.

No contexto das mudanças institucionais, destaca-se as alterações nas normativas contábeis no mundo, face ao processo de convergência às normas internacionais de contabilidade emitidas pelo IASB. Estas normas surgiram devido as necessidades das empresas a se adaptarem ao novo contexto de globalização, de forma a minimizar as diferenças contábeis em todo o mundo, possibilitando o aprimoramento da informação contábil como relevância, compreensibilidade, comparabilidade e confiabilidade (LISZBINSKI ET.AL, 2014).

Segundo Zuccolotto, Silva e Emmerndoerfer (2010) a contabilidade está a margem de instituições e pressões ambientais que definem a sua utilização. Nesta área do conhecimento, sob a ótica da regra, há um conjunto de procedimentos e técnicas definidas formalmente e registrados em manuais, também há rotinas que podem se caracterizar institucionalizadas quando são amplamente utilizadas e aceitas de forma inquestionável. Esta visão institucional explica os fenômenos contábeis a partir de padrões de comportamento, crenças, normas e procedimentos aos quais as organizações se reportam na intenção de ganhar eficiência e legitimidade no ambiente em que estão inseridas.

Encerra-se aqui a revisão da literatura, em que foi abordado a Proposta de Currículo pela ONU/ISAR/UNCTAD e o CFC, também a convergência das normas internacionais de contabilidade e a Teoria Institucional. No tópico seguinte é tratado os aspectos metodológicos.

\section{Procedimentos Metodológicos}

A população inicial deste trabalho é constituída pelas instituições de ensino superior existentes no Brasil que oferecem o curso de graduação em ciências contábeis na modalidade presencial e que estavam cadastradas no Ministério da Educação (MEC) e em atividade no período da pesquisa, ou seja, o ano de 2014. No cadastro do MEC encontrou-se 998 instituições de ensino superior que oferecem o curso de graduação em ciências contábeis na modalidade presencial. A pesquisa foi focada nas disciplinas em que houvesse probabilidade de estarem contidos nas suas ementas e/ou nos conteúdos programáticos conhecimentos inerentes aos pronunciamentos técnicos emitidos pelo Comitê de Pronunciamentos Contábeis (CPC). Em cada IES pertencente a amostra foi coletada a grade curricular do curso de Ciências Contábeis, 
após a coleta da grade, foi selecionado as disciplinas ligadas a área de contabilidade, como Contabilidade Introdutória, Contabilidade Avançada, Contabilidade de Custos, Contabilidade Fiscal, Teoria da Contabilidade, entre outras, pois nestas disciplinas há uma probabilidade maior de os CPCs estarem contemplados no conteúdo programático. As disciplinas como Matemática Financeira, Português, Psicologia Organizacional, Econometria, Introdução a Economia entre outras, não foram selecionadas, pois com a experiência dos pesquisadores, observa-se que nestas disciplinas os CPCs não estão contemplados.

A amostra foi definida de acordo com a disponibilidade dos dados. Primeiro buscou-se nas páginas eletrônicas das IES as ementas, os conteúdos programáticos e as grades curriculares dos cursos de ciências contábeis. Também foram solicitadas as informações aos coordenadores de curso por meio de correio eletrônico.

Dentre as 998 IES pertencentes à população do estudo, foi considerada uma amostra selecionada para a análise dos dados, definida pelas IES que disponibilizaram as ementas e os conteúdos programáticos nas suas páginas eletrônicas ou que os enviaram por meio de correio eletrônico. Entre as 998 IES pesquisadas, 130 IES disponibilizaram as ementas e/ou conteúdo programático, e dessas foram excluídas 25 IES por disponibilizarem ementas com informações insuficientes para análise. Portanto, fazem parte da amostra final do estudo 105 IES que oferecem o curso de ciências contábeis na modalidade presencial. As ementas e os conteúdos programáticos foram completamente analisados.

Neste estudo foram analisadas as IES por região: Sul, Sudeste, Nordeste, Centro-Oeste e Norte. Na Tabela 1 são evidenciadas a população e a amostra por região do Brasil.

Tabela 1 - População e amostra por região

\begin{tabular}{|c|c|c|c|}
\hline Região & População $\left(\mathrm{N}^{\circ}\right)$ & Amostra $\left(\mathrm{N}^{\circ}\right)$ & Amostra (\%) \\
\hline Sul & 196 & 32 & $16,3 \%$ \\
\hline Sudeste & 431 & 36 & $8,4 \%$ \\
\hline Nordeste & 197 & 21 & $10,7 \%$ \\
\hline Centro-Oeste & 95 & 10 & $10,5 \%$ \\
\hline Norte & 79 & 6 & $7,6 \%$ \\
\hline Total & 998 & 105 & $10,5 \%$ \\
\hline
\end{tabular}

Fonte: Elaborado pelo autor, 2014.

Foram objeto de análise, também, as ementas e os conteúdos programáticos referentes à Organização Acadêmica das IES, divididas em Centros Universitários, Faculdades e Universidades. Além disso, analisaram-se as ementas e os conteúdos programáticos referentes à categoria acadêmica das IES, subdivididas em públicas e privadas. A caracterização da amostra conforme organização e categoria acadêmica é apresentada na Tabela 2.

Tabela 2 - Amostra conforme organização e categoria acadêmica

\begin{tabular}{ccccc}
\hline Categoria/Organização & $\begin{array}{c}\text { Centros } \\
\text { Universitários }\end{array}$ & Faculdades & Universidades & Total \\
\hline Pública & - & 3 & 25 & 28 \\
\hline Privada & 15 & 47 & 15 & 77 \\
\hline Total & 15 & 50 & 40 & 105 \\
\hline
\end{tabular}

Fonte: Elaborado pelo autor, 2014.

Nas ementas e nos conteúdos programáticos analisou-se se os CPCs, que são os pronunciamentos técnicos emitidos pelo Comitê de Pronunciamentos Contábeis, estão contidos 
nas ementas e conteúdos programáticos das IES pertencentes à amostra no período do estudo, ou seja, no ano de 2014. Fazem parte da amostra os 45 CPCs aprovados pelo Comitê de Pronunciamentos Contábeis até dezembro de 2014. Os CPCs são evidenciados no Quadro 1.

Quadro 1 - Pronunciamentos Técnicos emitidos pelo Comitê de Pronunciamentos Contábeis

\begin{tabular}{|l|l|l|l|l|l|l|}
\hline \multicolumn{7}{|c|}{ Pronunciamentos Técnicos emitidos pelo CPC } \\
\hline CPC 00 & CPC 07 & CPC 15 & CPC 22 & CPC 29 & CPC 37 & CPC 45 \\
\hline CPC 01 & CPC 08 & CPC 16 & CPC 23 & CPC 30 & CPC 38 & CPC 46 \\
\hline CPC 02 & CPC 09 & CPC 17 & CPC 24 & CPC 31 & CPC 39 & CPC PME \\
\hline CPC 03 & CPC 10 & CPC 18 & CPC 25 & CPC 32 & CPC 40 & - \\
\hline CPC 04 & CPC 11 & CPC 19 & CPC 26 & CPC 33 & CPC 41 & - \\
\hline CPC 05 & CPC 12 & CPC 20 & CPC 27 & CPC 35 & CPC 43 & - \\
\hline CPC 06 & CPC 13 & CPC 21 & CPC 28 & CPC 36 & CPC 44 & - \\
\hline
\end{tabular}

Fonte: Elaborado pelo autor, 2014.

Para analisar se os conhecimentos relativos aos CPCs estavam contidos nas ementas e/ou nos conteúdos programáticos das IES que oferecem o curso de ciências contábeis na modalidade presencial, foram coletados dados junto às instituições, de modo que se pudesse identificar os pronunciamentos para posterior análise.

Primeiro realizou-se uma pesquisa na página eletrônica do Ministério da Educação na intenção de identificar as IES que oferecem o curso de ciências contábeis na modalidade presencial. Após tabuladas as instituições, buscou-se na página eletrônica de cada uma as ementas e os conteúdos programáticos. Nos casos em que as IES que não disponibilizaram as ementas e os conteúdos programáticos, estes foram solicitados aos coordenadores de curso das disciplinas em que houvesse probabilidade de algum CPC estar contido.

Após tabulados os dados referente às IES que oferecem o curso de Ciências Contábeis na modalidade presencial e as ementas e conteúdos programáticos de cada instituição, adotouse os seguintes critérios de análise de dados:

1 - Analisou-se as ementas e os conteúdos programáticos das disciplinas em que houvesse probabilidade de algum CPC estar contido, como, por exemplo, contabilidade societária, contabilidade internacional e contabilidade agropecuária, entre outras. Já disciplinas como matemática financeira, psicologia organizacional etc., em que certamente não será encontrado nenhum CPC, não foram analisadas.

2 - Para análise de aderência das IES em relação aos CPCs, estipulou-se um ponto para cada CPC contido nas ementas e/ou conteúdos programáticos da cada IES. Os dados foram organizados e tabulados em planilhas. Verificou-se em cada IES a quantidade de CPCs contidos nas ementas e/ou conteúdos programáticos e dividiu-se a quantidade total de CPCs identificados pela quantidade total de CPCs contidos na amostra, no caso, 45 pronunciamentos. Dessa maneira, obteve-se o índice de aderência de cada IES em relação aos CPCs, sendo este índice identificado pela sigla IA CPC, ou seja, Índice de Aderência aos CPCs. Esse critério também foi adotado na análise de aderência das IES por região, organização acadêmica e categoria acadêmica.

3 - Para identificar se os CPCs estavam contidos nas ementas e nos conteúdos programáticos em cada instituição, verificou-se nas próprias ementas e nos conteúdos programáticos se era mencionado o nome do CPC ou se mencionava o conteúdo referente ao CPC, caso em que se adotou o critério de interpretação do autor. Nas ementas e conteúdos programáticos de algumas IES evidenciou-se, por exemplo, Receita (CPC 30), em outras IES apenas CPC 30 e outras IES apenas Receita. Na IES em que constava somente a palavra 
"Receita" nas ementas e nos conteúdos programáticos foi considerado como presente o CPC 30, e quantificou-se como um ponto. Esse critério também foi adotado para os demais CPCs. No caso de CPCs que foram parcialmente adotados (como, por exemplo, o CPC 26), ainda que em algumas IES não estivessem contidas todas as demonstrações contábeis, foi considerado um ponto, pois a IES o contemplou, embora, em alguns casos, não tenha apresentado as demonstrações por completo.

$4-\mathrm{Na}$ análise de aderência dos CPCs em relação às IES também se estipulou um ponto para cada CPC contido nas ementas e/ ou conteúdos programáticos de cada IES. Os dados foram organizados e tabulados em planilhas. Obteve-se, assim, a soma total de pontos de cada CPC e dividiu-se pela quantidade total de IES pertencentes a amostra, no caso, 105 IES. Dessa maneira obteve-se o índice de aderência dos CPCs em relação às IES.

5 - No estudo foram expostas as estatísticas descritivas de cada região do Brasil (Sul, Sudeste, Norte, Nordeste e Centro-Oeste). Também foram apresentadas por organização acadêmica (Centros Universitários, Faculdades e Universidades) e por categoria acadêmica (pública e privada). Para análise de diferenças entre médias por região, organização acadêmica e categoria acadêmica, adotou-se o teste de igualdade de médias pelo método Wilcoxon/MannWhitney. Também foi realizado o teste de normalidade.

Segundo Stevenson (1981), o Teste de Mann-Whitney é usado para testar se duas amostras independentes provêm de populações com distribuições iguais. A hipótese alternativa é que uma das amostras provenha de uma população estatisticamente maior do que a outra. Dessa maneira, o teste também pode ser utilizado para observar diferenças entre médias das amostras. Como este teste é não paramétrico, ele pode ser utilizado quando as amostras não apresentam distribuição normal.

Em relação à identificação das IES, foram adotados nomes fictícios para que as informações de cada uma se mantenham sob sigilo, conforme impõe o rigor científico. A nomenclatura adotada para identificação das IES estabelece uma sigla que é referente ao estado de origem da IES, seguida de uma numeração escolhida de acordo com os controles internos do autor da pesquisa.

Uma limitação do método a ser considerada é o fato de algumas ementas e conteúdos programáticos possuírem características subjetivas, o que pode ter ocasionado a não identificação de algum CPC no estudo. Por fim, os resultados obtidos neste estudo não podem ser generalizados para outras populações e amostras, mas podem ser considerados consistentes na sua qualidade e extensão. Concluído o capítulo referente aos procedimentos metodológicos, segue análise dos dados da pesquisa.

\section{Análise dos Dados}

Uma vez tabulados os dados e definidos os pontos atribuídos a cada IES em relação aos CPCs, foi possível avaliar a aderência das IES aos CPCs. Primeiro, examinou-se a aderência, conforme dados apresentados resumidamente na Tabela 3. Com base nos dados evidenciados na Tabela 3, observa-se que a IES que possui um maior nível de aderência aos CPCs é a IES RJ42, com 75,6\%. Seguindo a RJ42 está a IES RN15 com 73,3\% de aderência. Com o mesmo percentual de aderência, as IES RS36; SP21 e SP22 possuem aderência de $60 \%$ cada uma delas.

As IES BA4 e MG40 apresentam 53,3\% de aderência aos CPCs, seguidas de quatro IES com aderência de 51,1\%, a saber, as IES MA4 RJ14 RS52 e SP237. As demais instituições possuem aderência inferior a 50\%. Também com base nos dados apresentados na Tabela 3 , pode-se observar que quinze IES possuem aderência de $31,1 \%$ aos CPCs. Já as IES que possuem um menor nível de aderências aos CPCs são a MS21 e a RO14, cada uma com 20\% de aderência. 
Tabela 3 - Índice de aderências das IES brasileiras em relação aos CPCs

\begin{tabular}{|c|c|c|c|}
\hline IES & $\operatorname{IES}\left(\mathrm{N}^{\circ}\right)$ & $\begin{array}{c}\mathrm{CPCs} / \mathrm{IES} \\
\left(\mathrm{N}^{\circ}\right)\end{array}$ & IA CPC $(\%)$ \\
\hline RJ42 & 1 & 34 & 75,6 \\
\hline RN15 & 1 & 33 & 73,3 \\
\hline RS36 - SP21 - SP22 & 3 & 27 & 60,0 \\
\hline BA4 - MG40 & 2 & 24 & 53,3 \\
\hline MA4 - RJ14 - RS52 - SP237 & 4 & 23 & 51,1 \\
\hline SC27 - SC52 & 2 & 22 & 48,9 \\
\hline AL11 - GO40 - MG93 - PE36 - SC4 - SP204 & 6 & 21 & 46,7 \\
\hline MG47 - SC41 - SC42 & 3 & 20 & 44,4 \\
\hline PE30 - RN16 - RS41 - RO1 & 4 & 19 & 42,2 \\
\hline $\begin{array}{l}\text { CE20 - CE22 - ES21 - MG3 - MG4 - MG96 - PR77 - RS23 - SC49 - SP8 - } \\
\text { TO3 }\end{array}$ & 11 & 18 & 40,0 \\
\hline $\begin{array}{l}\text { BA34 - GO4 - MS18 - MG10 - MG103 - MG104 - RJ15 - RS55 - RR4 - } \\
\text { SC30 - SE8 }\end{array}$ & 11 & 17 & 37,8 \\
\hline GO15 -MG23 - MG46 - PR46 - PR64 - RJ24 - RN5 - RN7 - RS49 - SC9 & 10 & 16 & 35,6 \\
\hline $\begin{array}{l}\text { BA52 - MG9 - MG11 - MG105 - RJ8 - RS20 - RS31 - RS60 - SC50 - SC54 } \\
\text { - SP200 }\end{array}$ & 11 & 15 & 33,3 \\
\hline $\begin{array}{l}\text { AM7 - GO18 - MG2 - MG26 - MG76 - PB12 - PR17 - PR74 - PR81 - PE5 } \\
\text { - RJ41 - RN17 - RO5 - SC44 - SE7 }\end{array}$ & 15 & 14 & 31,1 \\
\hline MT8 - MT19 - MG91 - MG98 - PB11 - PR35 - PI5 - RN14 - RS40 - SC47 & 10 & 13 & 28,9 \\
\hline MS17- MG34 - PR60 - RJ40 - SC8 - SP215 & 6 & 12 & 26,7 \\
\hline MT14 - PR54 - SP16 & 3 & 11 & 24,4 \\
\hline MS21 - RO14 & 2 & 9 & 20,0 \\
\hline Total & 105 & 45 & 100,0 \\
\hline
\end{tabular}

Fonte: Elaborado pelo autor, 2014

Observa-se na Tabela 3 que 94 IES possuem nível de aderência em relação aos CPCs inferior a $50 \%$, ou seja, $90 \%$ da amostra, e $10 \%$ da amostra possuem aderência acima de $50 \%$. Estes resultados são condizentes com o estudo de Campos e Lemes (2011) que analisaram a aderência dos Cursos de Ciências Contábeis em Universidades Federais do sul do Brasil com o Currículo Mundial proposto pela ONU/ISAR/UNCTAD. No que tange a contabilidade internacional no Bloco 4, a aderência média é de $39 \%$, ou seja, o nível de aderência a contabilidade internacional é inferior a 50\%, assim como evidenciado na Tabela 3, o nível de aderência aos CPCs é inferior a 50\%.

Observa-se no Gráfico 1 que a aderência média nacional e por região das IES em relação aos CPCs é inferior a 40\%. A média nacional é de 37,3\%. Na Região Sul é de 36,8\%; na Região Sudeste, 38,8\%; na Região Nordeste, 39,3\%, na Região Centro-Oeste, 31,7\% e, na Região Norte, 33,7\%. Também é evidenciado no Gráfico 9 que a média nacional e por região das IES em relação aos CPCs é superior a 30,0\%.

Os índices médios de aderência das regiões Sul, Centro-Oeste e Norte são inferiores comparados com o índice médio de aderência nacional. Já nas regiões Sudeste e Nordeste os índices de aderência são superiores ao índice médio de aderência nacional. A região com maior índice de aderência em relação aos CPCs é a região Nordeste, já a região com menor índice é a região Centro-Oeste.

Os resultados evidenciados no Gráfico 1 são condizentes com o estudo de Niyama et. al (2008), que analisaram a aderência das instituições de ensino superior localizadas nas capitais brasileiras em relação ao conhecimento de contabilidade internacional. Os autores concluíram 
que nem todas as IES capacitam os estudantes quanto à contabilidade internacional, uma explicação para os resultados encontrados por Niyama et al. (2008) pode ser observado no Gráfico 1, em que a aderência média nacional e por regiões das IES em relação aos CPCs é inferior a $40 \%$

\section{Gráfico 1 - Índice de aderência média nacional e por região das IES em relação aos CPCs}

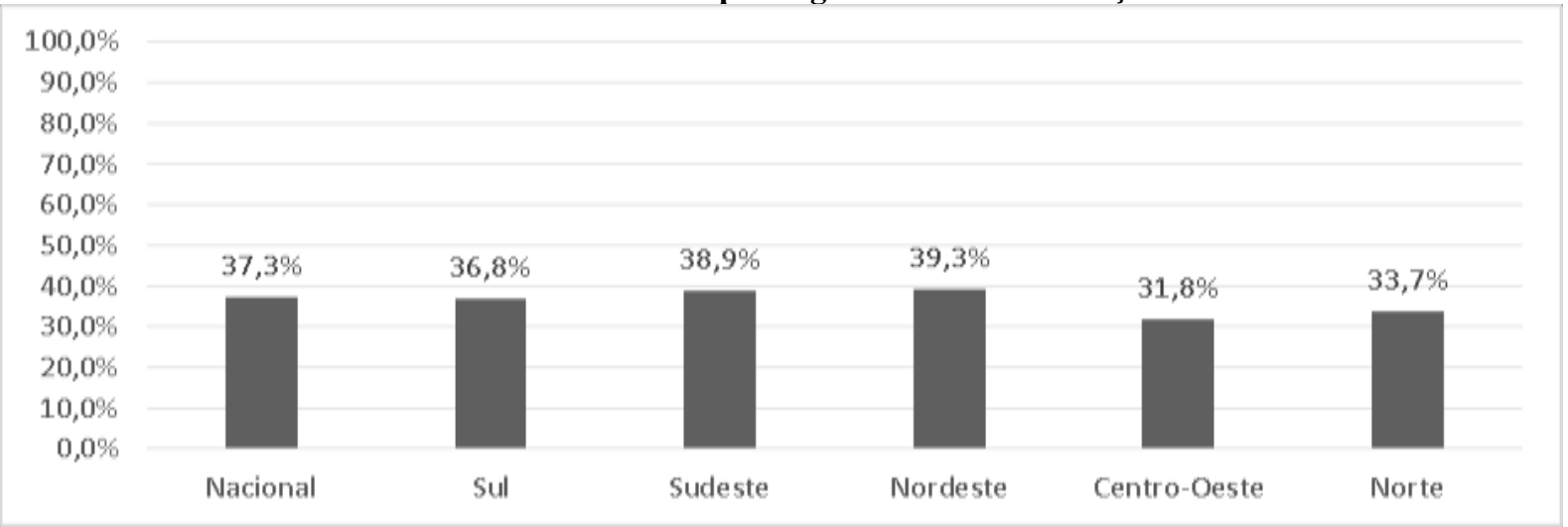

Fonte: Elaborado pelo autor, 2014.

Um dos motivos para o baixo índice de aderências das IES em relação aos CPCs pode ser devido a falta de professores qualificados para ensinar os CPCs. Também outra hipótese seja o número reduzido da carga horária destinado as disciplinas específicas de Contabilidade, sendo que nos Cursos de Ciências Contábeis a carga horária é distribuída em entre várias disciplinas em diversas áreas do conhecimento como matemática, psicologia, português, econômica, estatística entre outras. Essas afirmações são apenas hipóteses que serve de recomendação para estudos futuros.

Também se apresenta a análise descritiva geral dos níveis médios de aderência das IES em relação aos CPCs. São evidenciadas na Tabela 4 as estatísticas descritivas, com a média, a mediana, o máximo e mínimo de aderência das IES em relação aos CPCs no Brasil e por região.

Tabela 4 - Análise descritiva dos índices de aderência das IES em relação aos CPCs por região

Análise descritiva geral dos índices de aderência por região

\begin{tabular}{|c|c|c|c|c|c|c|}
\hline Aderência & Brasil & Sul & Sudeste & Nordeste & Centro-Oeste & Norte \\
\hline Média & 0,3739 & 0,3687 & 0,3888 & 0,3936 & 0,3177 & 0,3370 \\
\hline Mediana & 0,3555 & 0,3555 & 0,3666 & 0,3777 & 0,3000 & 0,3444 \\
\hline Máximo & 0,7555 & 0,6000 & 0,7555 & 0,7333 & 0,4666 & 0,4222 \\
\hline Mínimo & 0,2000 & 0,2444 & 0,2444 & 0,2888 & 0,2000 & 0,2000 \\
\hline Jarque-Bera & 61,9689 & 4,1961 & 17,5928 & 16,1615 & 0,3483 & 0,5762 \\
\hline Probabilidade & 0,0000 & 0,1226 & 0,0001 & 0,0003 & 0,8401 & 0,7496 \\
\hline Total IES & 105 & 32 & 36 & 21 & 10 & 6 \\
\hline
\end{tabular}

Fonte: Elaborado pelo autor, 2014.

Observa-se na Tabela 4 que a aderência média nas IES em relação aos CPCs no Brasil é de 37,3\%. Nas regiões Sul, Sudeste, Nordeste, Centro-Oeste e Norte os índices de aderência são $36,8 \%, 38,8 \%, 39,3 \%, 31,7 \%$ e 33,7\%, respectivamente. Em relação à mediana, no Brasil o índice é de 35,5\%, enquanto nas regiões Sul, Sudeste, Nordeste, Centro-Oeste e Norte os índices são, respectivamente, de 35,5\%,36,6\%, 37,7\%, 30\% e 34,4\%. O índice 
máximo de aderência das IES em relação aos CPCs no Brasil é de 75,5\%, alcançado por uma IES localizada na Região Sudeste. O índice mínimo de aderência, por sua vez, é de $20 \%$, alcançado por IES localizadas na região Centro-Oeste e Norte.

A probabilidade do teste Jarque-Bera, evidenciado na Tabela 4, informa que no Brasil a amostra de aderência não é normalmente distribuída. Analisando as informações por região, as regiões Sul, Centro-Oeste e Norte possuem distribuição normal, o que não ocorre com Sudeste e Nordeste.

$\mathrm{Na}$ Tabela 5 foi elaborado o teste de igualdade de médias pelo método Wilcoxon/MannWhitney por regiões. Observa-se que nos testes para as regiões Sudeste/Centro-Oeste e para Nordeste/Centro-Oeste a diferença entre médias é estatisticamente significante, o que se comprova pela probabilidade de 0,0551 entre Sudeste/Centro-Oeste e 0,0265 entre Nordeste/Centro-Oeste.

Comparando as regiões Sul/Sudeste, Sul/Nordeste, Sul/Centro-Oeste, Sul/Norte, Sudeste/Nordeste, Sudeste/Norte, Nordeste/Norte e Centro-Oeste/Norte evidenciadas na Tabela 5, a diferença entre as médias estatisticamente não tem significância, já que a probabilidade de cada uma está acima de 0,1 .

Tabela 5 - Teste de igualdade de médias pelo método Wilcoxon/Mann-Whitney

\begin{tabular}{|c|c|c|}
\hline Região & Valor & Probabilidade \\
\hline Sul-Sudeste & 0,5529 & 0,5803 \\
\hline Sul- Nordeste & 0,6819 & 0,4953 \\
\hline Sul - Centro Oeste & 1,6242 & 0,1043 \\
\hline Sul - Norte & 0,5804 & 0,5616 \\
\hline Sudeste-Nordeste & 0,2233 & 0,8233 \\
\hline Sudeste - Centro Oeste & 1,9174 & 0,0552 \\
\hline Sudeste - Norte & 0,7907 & 0,4291 \\
\hline Nordeste - Centro Oeste & 2,2185 & 0,0265 \\
\hline Nordeste - Norte & 0,6706 & 0,5024 \\
\hline Centro Oeste - Norte & 0,6507 & 0,5152 \\
\hline
\end{tabular}

Fonte: Elaborado pelo autor, (2014)

$\mathrm{Na}$ intenção de evidenciar uma comparação entre as médias de aderência das IES públicas e privadas apresenta-se no Gráfico 2 um paralelo entre as instituições. As IES públicas possuem índice médio de aderência de $37,9 \%$ e as IES privadas possuem índice médio de aderência de $37,2 \%$.

Os resultados evidenciados no Gráfico 2 são condizentes com os resultados encontrados por Frosi (2013) que analisou o alinhamento dos currículos dos Cursos de Ciências Contábeis em IES públicas e privadas com a proposta de currículo do Conselho Federal de Contabilidade. Embora o estudo de Frosi (2013) não relacione diretamente os CPCs e as normais internacionais de contabilidade, os quais também estão inseridos na proposta de currículo do Conselho Federal de Contabilidade, é possível inferir que os resultados são condizentes, ambos os estudos encontraram uma aderência maior nas IES Públicas.

Quanto à análise descritiva do nível médio de aderência das IES públicas e privadas em relação aos CPCs, são evidenciados na Tabela 6 os índices, média, mediana, máximo e mínimo de aderência dessas instituições. 
Gráfico 2 - Índice médio de aderência de IES públicas e privadas em relação aos CPCs.

\begin{tabular}{|c|c|c|}
\hline $100,0 \%$ & & \\
\hline $80,0 \%$ & $37,9 \%$ & $37,2 \%$ \\
\hline $60,0 \%$ & & \\
\hline $40,0 \%$ & & \\
\hline $20,0 \%$ & Públicas & Privadas \\
\hline $0,0 \%$ & & \\
\hline
\end{tabular}

Fonte: Elaborado pelo autor, 2014.

Observa-se na Tabela 6 que a média de aderência das IES públicas em relação aos CPCs é de $37,9 \%$ e nas IES privadas é de $37,2 \%$. No tocante à mediana nas IES públicas e privadas, o índice de aderência é de 35,5\%. O índice máximo de aderência nas IES públicas é de 75,5\% e nas IES privadas é de $60 \%$. Já o índice mínimo de aderência nas IES públicas e privadas é de $20 \%$. Com referência à probabilidade do Jarque-Bera evidenciada na Tabela 6 , observa-se que a amostra dos índices de aderência das IES públicas e privadas não possui distribuição normal.

Tabela 6 - Análise descritiva índices de aderência IES públicas e privadas

\begin{tabular}{lcc}
\hline \multicolumn{3}{c}{ Análise descritiva índices de aderência IES públicas e privadas } \\
\hline Aderência & Pública & Privada \\
\hline Média & 0,3793 & 0,3720 \\
\hline Máximo & 0,3555 & 0,3555 \\
\hline Mínimo & 0,7555 & 0,6000 \\
\hline & 0,2000 & 0,2000 \\
\hline Jarque-Bera & & \\
\hline Probabilidade & 34,8860 & 6,4019 \\
\hline Total Observações & 0,0000 & 0,0407 \\
\hline
\end{tabular}

Fonte: Elaborado pelo autor, 2014.

Na Tabela 7 apresenta-se o teste de igualdade de médias pelo método Wilcoxon/MannWhitney entre as IES públicas e privadas. Observa-se que nos testes para IES públicas e privadas a diferença entre médias não possui significância estatística. Isto se comprova pela probabilidade de 0,9221 evidenciada na Tabela 15 .

Tabela 7 - Teste de igualdade de médias pelo método Wilcoxon/Mann-Whitney nas IES públicas e privadas

\begin{tabular}{ccc}
\hline \multicolumn{3}{c}{ Teste de Igualdade de Médias/Wilcoxon/Mann-Whitney } \\
\hline IES & Valor & Probabilidade \\
\hline Públicas/Privadas & 0,0978 & 0,9221 \\
\hline
\end{tabular}

Fonte: Elaborado pelo autor, 2014.

Também se buscou avaliar os índices de aderência das IES em relação aos CPCs por organização acadêmica mediante a classificação em centros universitários, faculdades e universidades. A comparação entre estas é evidenciada no Gráfico 3, no qual se observa que o 
índice de aderência dos centros universitários é de $40,2 \%$, o das faculdades é de $36 \%$ e o das universidades é de $38 \%$.

Gráfico 3 - Índice médio de aderência das organizações acadêmicas em relação aos CPCs

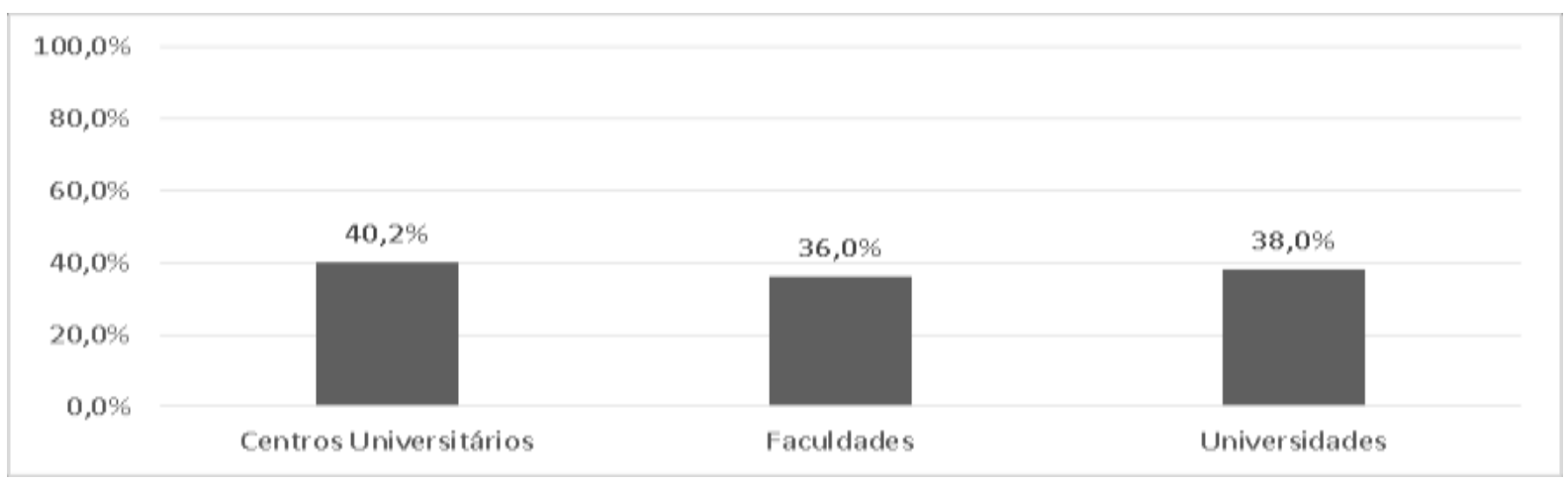

Fonte: Elaborado pelo autor, 2014.

No que tange à análise descritiva dos níveis médios de aderências das IES em relação aos CPCs, classificadas por organização acadêmica, são evidenciados na Tabela 8 os índices médios, a mediana, os índices máximos e mínimos de aderência.

$\mathrm{Na}$ Tabela 8 é evidenciado que o índice médio de aderência nos centros universitários em relação aos CPCs é de $40,2 \%$, ao passo que nas faculdades é de $36 \%$ e nas universidades, $38 \%$. Quanto à mediana, os centros universitários apresentam índices de aderência de $40 \% \mathrm{e}$ as faculdades e universidades apresentam índices de 35,5\% cada. O índice máximo de aderência dos centros universitários e faculdades é de $60 \%$, e nas universidades o índice máximo é de $75,5 \%$. De outra parte, o índice mínimo de aderência nos centros universitários é de $24,4 \%$ e nas faculdades e universidades é de $20 \%$.

A probabilidade do teste Jarque-Bera evidenciada na Tabela 8 informa que na amostra dos índices de aderência nos centros universitários a distribuição pode ser considerada normal, ao passo que nas faculdades e universidades não há evidências para considerar a distribuição normal.

Tabela 8 - Análise descritiva dos índices de aderência das IES aos CPCs por organização acadêmica

\begin{tabular}{|c|c|c|c|}
\hline \multicolumn{4}{|c|}{ Índices de aderência por Organização Acadêmica } \\
\hline Aderência & Centros Universitários & Faculdades & Universidades \\
\hline Média & 0,4029 & 0,3604 & 0,3800 \\
\hline Mediana & 0,4000 & 0,3555 & 0,3555 \\
\hline Máximo & 0,6000 & 0,6000 & 0,7555 \\
\hline Mínimo & 0,2444 & 0,2000 & 0,2000 \\
\hline Jarque-Bera & 0,9318 & 4,8312 & 41,2992 \\
\hline Probabilidade & 0,6275 & 0,0893 & 0,0000 \\
\hline Total Observações & 15 & 50 & 40 \\
\hline
\end{tabular}

Fonte: Elaborado pelo autor, 2014.

Na Tabela 9 é evidenciado o teste de igualdade de médias pelo método Wilcoxon/MannWhitney entre as organizações acadêmicas. Observa-se que nos testes para centros universitários/faculdades a diferença entre médias não é estatisticamente significante, o que se 
comprova pela probabilidade de 0,1454 evidenciada na Tabela 9. Comparando centros universitários e universidades, a diferença entre médias também não é estatisticamente distinta, conforme evidencia na Tabela 9 a probabilidade de 0,2730. E na comparação entre faculdades e universidades, também a diferença entre médias estatisticamente não é significante, já que a probabilidade é de 0,5398 .

Tabela 9 - Teste de igualdade de médias pelo método Wilcoxon/Mann-Whitney

\begin{tabular}{lcc}
\hline \multicolumn{3}{c}{ Teste de Igualdade de Médias/Wilcoxon/Mann-Whitney } \\
\hline \multicolumn{1}{c}{ Organização Acadêmica } & Valor & Probabilidade \\
\hline Centros Universitários/Faculdades & 1,4557 & 0,1454 \\
\hline Centros Universitários/Universidades & 1,0960 & 0,2730 \\
\hline Faculdades/Universidades & 0,6130 & 0,5398 \\
\hline
\end{tabular}

Fonte: Elaborado pelo autor, 2014.

Concluída a análise geral de aderência das IES em relação aos CPCs por Organização Acadêmica, segue análise de aderência dos CPCs nas IES. Seguindo o estudo, realizou-se a análise dos índices de aderência dos CPCs em relação às IES, o que é evidenciado a seguir, incluindo os CPCs que não constam nas ementas e nos conteúdos programáticos das IES pertencentes à amostra.

$\mathrm{Na}$ tabela 10 verificou-se a quantidade de IES em que cada CPC foi contemplado. O CPC 43 - Adoção Inicial dos Pronunciamentos Técnicos CPC 15 a 41, o CPC 44 Demonstrações Combinadas e o CPC 45 - Divulgação de Participação em Outras Entidades não possuem aderência em relação às IES, pois não foram localizados nas ementas e nos conteúdos programáticos os respectivos CPCs.

Os CPCs com maiores índices de aderência são os CPC 00 - Estrutura Conceitual para Elaboração e Divulgação de Relatório Contábil-Financeiro, CPC16 - Estoques, CPC 26 Apresentação das Demonstrações Contábeis, CPC 27 - Ativo Imobilizado e CPC 30 - Receitas. Cada um dos CPCs citados foi contemplado em 105 IES do Brasil, ou seja, 100\% da amostra. Segue a Tabela 10 .

Tabela 10 - Aderência dos CPCs nas IES do Brasil

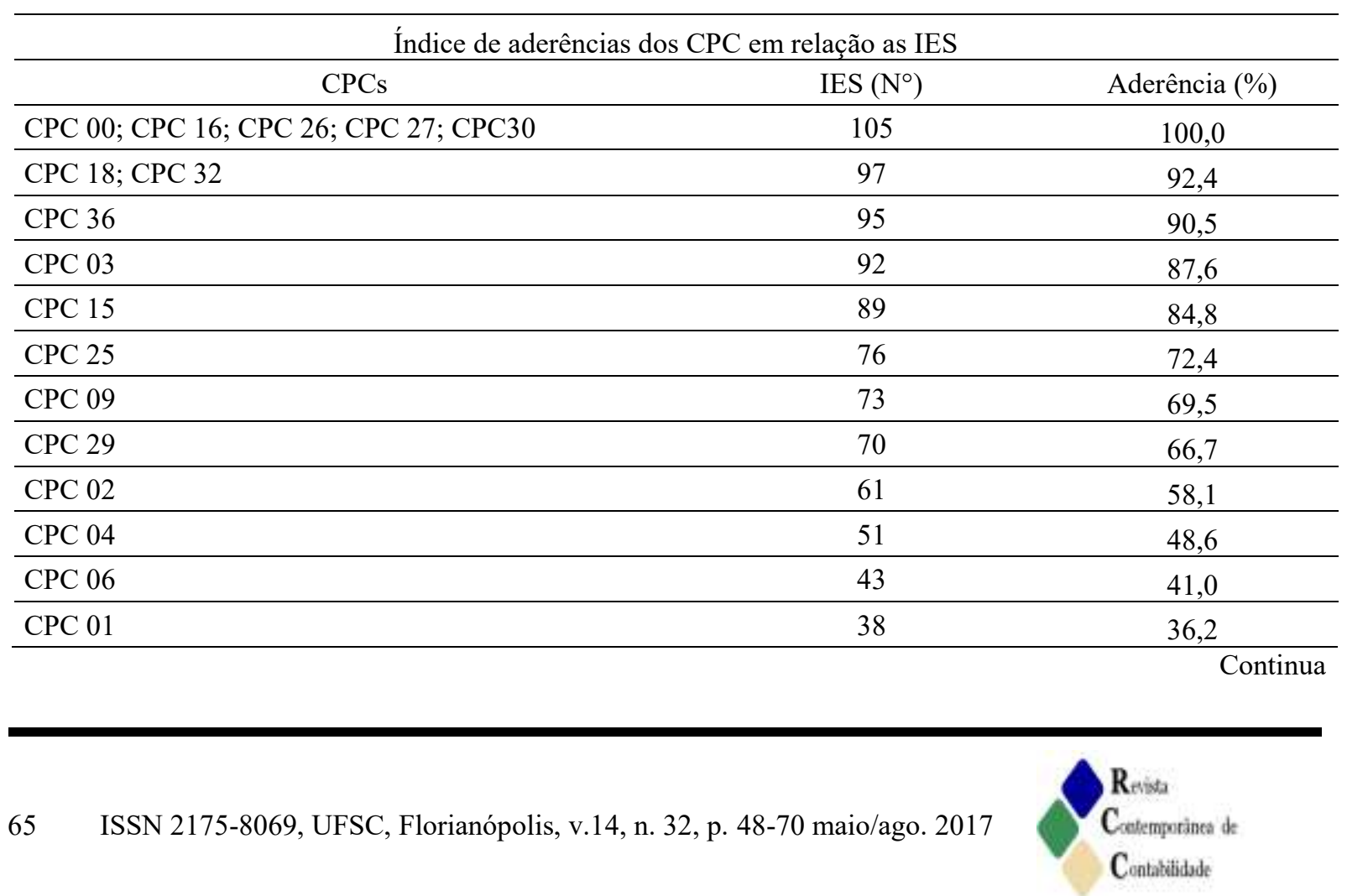




\begin{tabular}{|c|c|c|}
\hline \multicolumn{3}{|c|}{ Índice de aderências dos CPC em relação as IES } \\
\hline CPCs & $\operatorname{IES}\left(\mathrm{N}^{\circ}\right)$ & Aderência (\%) \\
\hline CРC 38 & 37 & 35,2 \\
\hline СРC 08 & 36 & 34,3 \\
\hline CPC 11 & 35 & 33,3 \\
\hline CPC 12 & 30 & 28,6 \\
\hline СРC 05 & 28 & 26,7 \\
\hline СРC 07 & 22 & 21,0 \\
\hline CPC 46 & 18 & 17,1 \\
\hline СРC PME & 17 & 16,2 \\
\hline СРC 17; СРC 19 & 16 & 15,2 \\
\hline CPC 23 & 12 & 11,4 \\
\hline СРC 33; СРC 40 & 11 & 10,5 \\
\hline CPC 37 & 10 & 9,5 \\
\hline СРC 24; СРC 39 & 9 & 8,6 \\
\hline CPC 28 & 8 & 7,6 \\
\hline CPC 20 & 7 & 6,7 \\
\hline СРC 21; СРC 22; СРC 31; СРC 35 & 5 & 4,8 \\
\hline СРC 10; СРC 41 & 3 & 2,9 \\
\hline CPC 13 & 2 & 1,9 \\
\hline СРС 43; СРС 44; СРС 45 & 0 & 0,0 \\
\hline
\end{tabular}

Fonte: Elaborado pelo autor, 2014

Observa-se na Tabela 10 que o CPC 32 - Tributos sobre o Lucro possui 92,4\% de aderência em relação as IES, isto confirma que a contabilidade no Brasil possui um enfoque significativo em Contabilidade Tributária, assim como a Rússia, em que no estudo de Vysotskaya e Prokifieva (2013) também verificaram um enfoque em Contabilidade Fiscal.

O Brasil adotou as normais internacionais de contabilidade em 2008 e conforme dados evidenciados na Tabela 10 referente ao ano de 2014, há muitos CPCs que não foram contemplados nas IES do Brasil, este resultado condiz com a afirmação de Bell (2011) que o processo de mudanças institucional é contínuo, lento e gradativo, passível de descontinuidade e ruptura. No que diz respeito ao ensino da contabilidade harmonizados as normas internacionais o processo de mudança está lento.

Conforme resultados evidenciados neste estudo, pode-se inferir que muitas IES ainda ensinam contabilidade como era ensinado anteriormente a adoção das normas internacionais de contabilidade, ou seja, possui os mesmos hábitos, isto vai de encontro com a Teoria Institucional, conforme destaca Hodgson (2006) que a nova economia institucional assume que os hábitos são consequência das escolhas racionais, mas para o autor os hábitos estão relacionados ao conhecimento e às crenças, sendo que o essencial das crenças ocorre devido ao estabelecimento de hábitos.

Neste tópico foi abordado a análise dos dados deste estudo, no tópico seguinte a conclusão e recomendações do estudo. 


\section{Conclusão e Recomendações}

Esta pesquisa avalia o alinhamento dos conteúdos de contabilidade constantes nos currículos dos cursos de ciências contábeis em IES no Brasil com os pronunciamentos técnicos do CPC, que têm origem nas normas internacionais de contabilidade. A amostra é composta por 105 IES que oferecem o curso de ciências contábeis na modalidade presencial, e os CPCs analisados são os 45 aprovados e divulgados pelo Comitê de Pronunciamentos Contábeis até dezembro de 2014.

Este estudo contribuiu para avaliar as IES que oferecem o curso de ciências contábeis no Brasil em relação ao ensino dos CPCs. Também, evidenciou que os contadores que estão entrando no mercado de trabalho ou que nele já estavam, concluído a graduação ou estando ainda por concluir, não estão adquirindo o conhecimento necessário nos CPCs devido ao baixo índice de CPCs contemplados nas IES.

Adicionalmente, é importante ressaltar que os resultados obtidos neste estudo não devem ser generalizados em razão do tamanho da amostra, mas podem ser considerados consistentes na sua qualidade e extensão. Considerando a aderência das IES brasileiras em relação aos CPCs, entre as 105 IES analisadas, apenas onze possuem aderência superior a 50\%. Já a média geral de aderências nas IES brasileiras em relação aos CPCs é de 37,3\%. É um índice baixo, considerando-se que são apenas 45 CPCs.

No estudo, não foram identificados nas ementas e nos conteúdos programáticos das IES o CPC 43 - Adoção Inicial dos Pronunciamentos Técnicos CPC 15 a 41, CPC 44 Demonstrações Combinadas e o CPC 45 - Divulgação de Participações em Outras Entidades.

Quanto aos índices de aderência dos CPCs nas IES, destaque-se que alguns CPCs não foram contemplados em algumas instituições. Muitos contadores podem estar entrando no mercado de trabalho sem o conhecimento necessário em relação aos CPCs e, consequentemente, podem ocasionar distorções nas informações contábeis e até mesmo prejuízo nas instituições.

O contador sem o conhecimento necessário no CPC 02 - Efeito das Mudanças nas Taxas de Câmbio e Conversão das Demonstrações Contábeis, CPC com índice de aderência de 58,1\% nas IES, pode efetuar a conversão de forma incorreta, não utilizando as devidas taxas de câmbio para o ativo, passivo, patrimônio líquido e resultado. Esse erro pode ocasionar uma diferença no cálculo da equivalência patrimonial, distorcendo as informações contábeis.

Em relação ao CPC 04 - Ativo Intangível, CPC este com índice de aderência de 48,6\% nas IES, a falta de conhecimento também pode gerar distorções nas informações contábeis, principalmente no ativo intangível gerado internamente, em que, na fase de pesquisa, os gastos devem ser contabilizados como despesa e, quando na fase de desenvolvimento, desde que atendam certos critérios, devem ser contabilizados como ativos intangíveis.

Também pode gerar distorções na contabilidade, se o contador não tiver o conhecimento necessário para contabilização, o arrendamento mercantil financeiro e operacional, tanto no arrendatário quanto no arrendador. O CPC 06 possui índice de aderência de 41\% nas IES.

Outro CPC com importância significativa no imobilizado e intangível é o CPC 01 Redução ao Valor Recuperável, com índice de aderência de $36,2 \%$ em relação às IES. O contador sem o conhecimento necessário neste CPC pode estar não fazendo a redução ao valor recuperável do imobilizado, intangível, ou pode estar calculando incorretamente ao comparar o valor em uso e o valor justo, causando distorções na contabilidade da empresa.

Conclui-se neste estudo que as IES no Brasil pertencentes à amostra possuem baixa aderência em relação aos CPCs, e o ensino da contabilidade harmonizado aos padrões internacionais necessita de melhorias, contemplando um número maior de CPCs nas ementas 
e/ou conteúdos programáticos das IES. É necessária uma mudança institucional para que haja melhoria no ensino da contabilidade no Brasil.

Envolvendo esta temática, recomenda-se para estudos futuros verificar se os índices de aderência das IES em relação aos CPCs possuem correlação com a quantidade de mestres e doutores nos cursos de ciências contábeis de cada IES. Também se sugere um estudo que relacione o desempenho das IES nos exames de suficiência do CFC e nas provas do Exame Nacional de Desempenho de Estudantes (Enade) aos índices de aderências das IES em relação aos CPCs.

\section{Referências}

AGGESTAM, C. Towards a global accounting qualification? A report from the $16^{\text {th }}$ session of the ISAR group of the UN palais de nations. The European Accounting Review, Geneva, v. 8 , n. 4, p. $805-813$, 1999. DOI: 10.1080/096381899335835

BELL, S. Do we really need a new "constructivist institutionalism" to explain institutional change? British Journal of Political Science. v.41, n.4, p.883-906, 2011. DOI: $10.1017 / \mathrm{S} 0007123411000147$

CAMPOS, L. C., LEMES, S. Análise comparativa entre o currículo mundial proposto pela ONU/UNCTAD/ISAR e as Universidades Federais da Região Sudeste. In: ENCONTRO DE ENSINO E PESQUISA EM ADMINISTRAÇÃO E CONTABILIDADE, 3., João Pessoa/PB, 2011. Anais... Disponível em: <http://www.anpad.org.br/diversos/trabalhos/EnEPQ/ enepq 2011/ ENEPQ419.pdf> Acesso em 10 Set. 2013.

CARVALHO, C.A; VIEIRA, M.M.F; SILVA, S.M.G. A trajetória conservadora da teoria institucional. Revista de Administração Pública - RAP, [S.1], v.39, n.4, 2005.

COMITE DE PRONUNCIAMENTOS CONTÁBEIS (CPC). [S.1.], 2013. Disponível em: $<$ http://www.cpc.org.br> Acesso em: 09 set.2013.

CONSELHO FEDERAL DE CONTABILIDADE (CFC). Proposta nacional de conteúdo para o curso de Graduação em Ciências Contábeis - 2º edição revista e atualizada, 2009. [S.1.], Disponível em: <http://www.cfc.org.br/uparq/proposta.pdf>. Acesso em: 08 jan. 2014.

CUNHA, E.V R. O Currículo e o seu planejamento: Concepções e práticas. Revista Espaço do Currículo, [S.1], v.3, n.2, p.578-590, 2011. DOI: 10.15687/rec

CZESNAT, A. O., CUNHA, J. V., DOMINGUES, M.J. C. S. Análise comparativa entre os currículos dos cursos de Ciências Contábeis das universidades do estado de Santa Catarina listadas pelo MEC e o currículo mundial proposto pela ONU/UNCTAD/ISAR. Gestão \& Regionalidade, [S.1.], v. 25, n. 75, p. 22, 2009. DOI: 10.13037/qr.vol25n75.186

CUNHA, P. R. et al. Reflexos da Lei $\mathrm{n}^{\circ} 11.638 / 07$ nos indicadores contábeis das empresas têxtis listadas na BM\&FBovespa. Revista de Educação e Pesquisa em Contabilidade, Brasília, v. 7, n. 2, art. 1, p. 112-130, 2013. DOI: 10.17524/repec.v7i2.153 
DIMAGGIO, P. J.; POWELL, W.W. The iron cage revisited institutional isomorphism and collective rationality in organizational fields. In: The New Institutionalism in Organizational Analysis. Chicago, v.48, n.2, p.147-160, 1983.

FROSI, M. Um estudo sobre o alinhamento dos currículos dos cursos de Ciências Contábeis de IES da região sul do Brasil com as propostas de currículo da ONU/UNCTAD/ISAr e do Conselho Federal de Contabilidade. Dissertação (Mestrado em Ciências Contábeis) -, Programa de Pós Graduação em Ciências Contábeis, Universidade do Vale do Rio dos Sinos - UNISINOS, São Leopoldo, 2013.

GOODLAD, J.I. Curriculum Inquirity. The study of curriculum practice. McGraw-Hill Inc, US, 1979.

HILTON, S.R.; JOHNSTONE, N. The IFRS transition and accounting education: A canadian perspective post-transition. Issues in Accounting Education. [S.1], v.28, n.2, p.253-261, 2013. DOI: $10.2308 /$ iace-50366

HODGSON, G.M. What Are Institutions? Journal of Economic Issue, v. xl, n. 1, 2006.

LISZBINSKI, B.B; KRONBAUER, C.A; MACAGNAN, C.B; PATIAS, T.Z. Conformidade no reconhecimento de ativos intangíveis: um estudo na perspectiva da teoria institucional.

Revista Contemporânea de Contabilidade, Florianópolis, v.11, $n^{\circ} .24$, p.85-106, 2014. DOI: $10.5007 / 2175-8069.2014 \mathrm{v} 11 \mathrm{n} 24 \mathrm{p} 85$

MAGALHÃES, F. A. C., ANDRADE, J. X. A educação contábil no estado do Piauí diante da proposta da convergência internacional do currículo de contabilidade concebida pela

ONU/UNCTAD/ISAR. In: CONGRESSO USP DE CONTROLADORIA E

CONTABILIDADE, 2006. Anais..., 2006. Disponível em:

$<$ http://www.congressousp.fipecafi.org/artigos62006/550.pdf $>$. Acesso em 06 set. 2013.

MALTA, S. C. L. Uma abordagem sobre currículo e teorias afins visando à compreensão e mudança. Revista Espaço do Currículo, [S.1], v.6, n.2, p.340-354, 2013. DOI: 10.15687/rec

MORAES, M. C. Complexidade e currículo: por uma nova relação. Polis, Revista de la Universidad Bolivariana. Santiago, v.9, n.25, p.289-311, 2010.

NIYAMA, J. K. et al. Conhecimento de contabilidade internacional nos cursos de graduação em Ciências Contábeis: estudo da oferta nas instituições de ensino superior das capitais brasileiras. Revista de Contabilidade e Organizações, [S.1.], v. 1.2(2), p.100, 2008.

NORTH, D. Instituciones, cambio institucional y desempeño edonómico. México: Foundo de Cultura Económica, 1995.

PELEIAS, I. R. et al. Evolução do ensino da contabilidade no Brasil: uma análise histórica. Revista Contabilidade \& Finanças, [S.1.], v.18, p.19-32, 2007.

PIRES, C. B. A formação e a demanda do mercado de trabalho do Contador na região metropolitana de Porto Alegre - RS. Dissertação (Mestrado em Ciências Contábeis) - 
Programa de Pós-Graduação em Ciências Contábeis, Universidade do Vale do Rio dos Sinos (UNISINOS), São Leopoldo, 2008.

RICCIO, E. L., SAKATA, M. C. G. Evidências da globalização na educação contábil: estudo das grades curriculares dos cursos de graduação em universidades brasileiras e portuguesas. Revista Contabilidade \& Finanças - USP. São Paulo, n. 35, p. 35-44, 2004.

RODRIGUES, A. T. L. et al. Proposta nacional de conteúdo para o curso de graduação em Ciências Contábeis. 2009. Disponível em: <http://50.97.105.38/ cfcor495/wordpress/wpcontent/uploads/2013/01/Proposta_Nacional_de_Conteudo.pdf $>$. Acesso em: 12 out. 2013.

SACRISTÁN, J.G. O currículo: uma reflexão sobre a prática. Tradução de Ernani F. da F. Rosa. 3ed. Porto Alegre: ArMed, 2000.

SCOTT, W. Ricard. The adolescence of institutional theory. Administrative Science Quartely, v.32, n.4, p.493-511, 1987.

SECKLER, D. Thorstein Veblen y el institucionalismo: um estúdio de la filosofia social de la economia. México: Fondo de Cultura Económica, 1977.

STEVENSON, W. J. Estatística Aplicada a Administração. São Paulo: Harbra, 1981.

VEBLEN, Thorstein. A teoria da classe ociosa. São Paulo: Pioneira Editora, 1965.

VYSOTSKAYA, A., PROKOFIEVA', M. The difficulties of teaching IFRS in Russia. Issues in Accounting Education, [S.1.], v. 28 n. 2, p. 309-319, 2013.

YAMAMOTO, M.P; ROMEU, S.A. Currículo: teoria e prática. In: D’ANTOLA A. (org). Supervisão e Currículo. São Paulo: Pioneira, 1983.

ZUCCOLOTTO, R; SILVA, G.M; EMMERNDOERFER, M.L. Limitações e possibilidade de compreensão da utilização das práticas de contabilidade gerencial por perspectivas da teoria institucional. BASE, v.7, n.3, p.233-246, 2010.

* Artigo apresentado no IX Congresso ANPCONT, Curitiba, PR, Brasil, 31 de maio a 03 de junho de 2015. 